\title{
Alterations of bone mineral density, bone microarchitecture and strength in patients with ankylosing spondylitis: a cross- sectional study using high-resolution peripheral quantitative computerized tomography and finite element analysis
}

Nisha Nigil Haroon', Eva Szabo', Janet M. Raboud', Heather Mcdonald-Blumer', Lydia Fung', Robert G. Josse', Robert D. Inman ${ }^{1}$ and Angela M. Cheung ${ }^{1,2^{*}}$

\begin{abstract}
Introduction: Ankylosing spondylitis (AS) is an inflammatory disease associated with new bone formation and an increased risk of osteoporosis and fractures. The negative effects of AS on bone microarchitecture and strength are unclear. Thus, we conducted an observational study to analyze the effect of AS on bone microarchitecture and strength.

Methods: Patients with AS ( $n=53)$ and non-AS subjects $(n=85)$ were recruited for the study. All subjects underwent clinical evaluation, DXA and high-resolution peripheral quantitative $C T$ scans (HRpQCT).

Results: The AS patients were aged $44 \pm 12$ (mean \pm standard deviation) years and had a median disease duration of 17 (interquartile range: 7-27) years. They were found to have lower cortical, trabecular and total VBMD at the distal radius and tibia than non-AS subjects on multivariable regression analysis. Cortical parameters such as cortical thickness and porosity, and bone strength parameters such bone stiffness and stress as estimated by finite element analysis (FEA) in AS patients were significantly worse than that of-non-AS subjects. Among patients with AS, male sex, mSASSS greater than zero and HLA-B27 negative status were associated with worse bone microarchitecture.

Conclusions: Patients with AS have worse bone mineral density, microarchitecture and strength when compared to non-AS subjects. More research is needed to understand the mechanisms underlying bone pathology in AS and to assess the effect of treatments such as TNF inhibitors on bone quality and fracture risk.
\end{abstract}

Keywords: High-resolution peripheral quantitative computerized tomography, Bone mineral density, Ankylosing spondylitis, Osteoporosis, Bone microarchitecture

\footnotetext{
* Correspondence: angela.cheung@uhn.ca

1 Department of Medicine, University of Toronto, Toronto, Canada

${ }^{2}$ Toronto General Hospital, University Health Network, Eaton 7th Floor Rm

7EN221, 200 Elizabeth St., Toronto, ON M5G 2C4, Canada
} 


\section{Introduction}

Ankylosing spondylitis (AS) is a spondyloarthropathic disorder that causes pain, fatigue, disability, morbidity, and mortality [1]. Patients with AS are at high risk of osteoporosis and vertebral fractures (VFs) [2]. In addition, non-VFs occur more frequently in AS patients $[2,3]$. Patients with AS were found to have a $35 \%$ increased risk of non-VFs in a large-scale study based on Danish health registries [3]. In 2014, a Spanish study reported a $19 \%$ higher risk for non-VFs [2]. Fractures can cause severe pain, deformity, disability, poor quality of life, financial burden, and even mortality.

The etiology of fractures in AS is unclear. Peripheral fractures might be mediated by the increased risk of falls because of hyperkyphosis $[4,5]$. Data regarding the association between low bone mineral density (BMD) and fractures in AS patients are inconsistent [6-10]. Both $\mathrm{BMD}$ and bone microarchitecture predict fracture risk $[11,12]$. However, data on bone loss in patients with AS are based on studies using dual-energy X-ray absorptiometry (DXA). DXA-based BMD is two-dimensional and cannot distinguish between bone compartments. This is a limitation while studying inflammatory diseases causing differential involvement of the cortical and trabecular compartments. Other limitations of DXA in AS include false elevation of spine BMD by syndesmophytes and difficulty in patient positioning on the DXA table due to spinal immobility and coxitis [13, 14]. Further, some patients undergo hip replacement, making the hip scan difficult to interpret.

Earlier reports suggest that AS patients have low trabecular BMD in the spine [15]. HLA-B27 transgenic rats have abnormal trabecular structure in the spine and lower structural strength in the femur [16, 17]. Abnormal bone strength possibly occurs due to inflammation and high bone turnover [17]. These findings need to be confirmed using newer techniques such as high-resolution peripheral quantitative computerized tomography (HRpQCT) that provides compartment-specific (trabecular versus cortical) information. HRpQCT-based finite element analysis (FEA) provides knowledge about the biomechanical properties [18-20]. Our aim was to investigate the differences in volumetric bone mineral density (vBMD), bone microarchitecture, and strength in patients with severe AS and in non-AS subjects using HRpQCT and FEA. We also studied the influence of sex, modified Stoke Ankylosing Spondylitis Spine Score (mSASSS), and HLA-B27 on bone parameters.

\section{Methods}

Patients were recruited from the spondylitis clinic located at Toronto Western Hospital, Canada. Our inclusion criteria were age $>18$ years and diagnosis of AS (modified New York criteria) [21]. All patients had been participating in a longitudinal study designed to assess the effect of tumor necrosis factor-alpha inhibitors (TNFi) on bone microarchitecture and hence had active disease (Bath Ankylosing Spondylitis Disease Activity Index (BASDAI) 24) [22]. Patients underwent all of the necessary laboratory tests, BMD, and HRpQCT just before starting TNFi. Eight patients declined participation, citing lack of time and significant pain. We excluded patients who had received TNFi and interleukin (IL)-12/23 inhibitors and pregnant women. Radiological severity of AS was documented by mSASSS (high mSASSS $=$ mSASSS $>0$ ) [23]. The comparison group consisted of non-AS subjects who had participated in the Toronto HRpQCT substudy of the Canadian Multicenter Osteoporosis Study (CaMOS), a random population-based sample of noninstitutionalized individuals (aged $\geq 25$ years) living within $50 \mathrm{~km}$ of Toronto [24].

\section{Assessment of areal BMD}

Areal BMD was measured at the femoral neck, total hip, L1-L4 spine, and distal radius (Hologic, Bedford, MA, USA). Osteoporosis was defined using WHO criteria [25]. Premenopausal women and men aged $<50$ years were considered to have low bone mass if the $Z$-scores were $\leq-2.0[26]$.

\section{HRpQCT}

HRpQCT was performed at the distal radius and tibia (XtremeCT; Scanco Medical, Bassersdorf, Switzerland). This scanner is equipped with a two-dimensional detector array and a $0.08 \mathrm{~mm}$ point-focus $\mathrm{X}$-ray tube. The measurement settings were: X-ray tube potential of 60 $\mathrm{kVp}$, current of $900 \mu \mathrm{A}$, and an image matrix size of $1536 \times 1536$. The limb positioning was secured inside a carbon-fiber shell. An anteroposterior scout view was acquired to determine the region of interest. A reference line was then placed at the end plate. We examined the areas of interest in 110 parallel two-dimensional slices. First slices were obtained at 9.5 and $22.5 \mathrm{~mm}$ proximal to the reference lines at the radius and tibia respectively. We separated the image slices into trabecular and cortical regions using a Gaussian filter and a thresholdbased algorithm. We derived HRpQCT parameters using the standard morphological analysis [27]. The cortical bone was automatically segmented to measure geometry, density, and microstructure using a manufacturersupplied algorithm [28]. The manufacturer's phantom was scanned daily for quality control. We used HRpQCT images to estimate biomechanical parameters using FEA $[18,29,30]$. We used the voxel-conversion approach to generate linear, homogeneous finite-element meshes from the images. The boundary conditions simulated a uniaxial compression test. The nodes at the top and bottom surfaces were unconstrained and displacement was applied in the uniaxial testing direction that corresponded to $1 \%$ 
strain. We applied a homogeneous tissue modulus of $6829 \mathrm{MPa}$ and a Poisson's ratio of 0.3.

\section{Statistical analysis}

We summarized categorical and continuous variables as frequencies (percentages) and means (standard deviations) or medians (interquartile ranges) respectively. Two-sample $t$ tests, Mann-Whitney $\mathrm{U}$ tests, or chi-square tests were used to compare intergroup differences. Multivariable linear regression analysis (adjusted for age and sex) was performed to study the effect of AS on HRpQCT parameters. We also examined the association between serum inflammatory markers and bone parameters using Pearson or Spearman correlation coefficients. The institutional research ethics board of the University Health Network, Toronto, Canada approved the study. All subjects gave written informed consent.

\section{Results}

\section{Demographic parameters}

The AS patients $(n=53)$ were mostly Caucasians $(75 \%)$ (Table 1). Two patients had VFs. Eight women were postmenopausal but none had received hormone therapy (HT).

Patients with mSASSS $>0 \quad(n=28)$ were significantly older and had longer disease duration than those with normal mSASSS $(\mathrm{mSASSS}=0)$ (Table 2). Age, disease duration, sex distribution, mSASSS, BASDAI, and body mass index (BMI) did not differ between AS patients with or without HLA-B27 antigen (Table 2).

The non-AS patients $(n=85)$ were mostly Caucasians (89\%), had a mean age of $61 \pm 8$ years, and $71 \%$ were women (Table 1). Five (6\%) and 13 non-AS subjects (15\%) used steroids and bisphosphonates respectively. Six (11\%) non-AS subjects had experienced fragility fractures and 16 (19\%) non-AS women had used HT. The total daily calcium intake was lower in AS patients than in non-AS patients (745 mg vs. $1045 \mathrm{mg}, p<0.05$ ). However, the use of supplemental vitamin D was similar between the two groups ( $36 \%$ vs. $38 \%$ ).

\section{Abnormalities in vBMD, bone structure, and strength in AS patients in comparison with non-AS subjects}

Multivariable regression analysis adjusted for differences in age and sex suggested that patients with AS $(n=53)$ had lower cortical and total vBMD at the distal radius and tibia than non-AS subjects $(n=85)$ (Table 3). Cortical thickness was reduced and cortical porosity increased in AS patients. Trabecular microarchitecture was not different between the two groups. FEA parameters at the radius (bone stiffness and stress) were negatively affected in AS patients (Table 3). Similar changes were noted at the distal tibia, and the beta coefficient showed a trend towards being statistically significant (Table 3).
Table 1 Clinical characteristics and areal BMD of AS patients and non-AS subjects

\begin{tabular}{|c|c|c|}
\hline Variable & AS patients & Non-AS subjects \\
\hline Number & 53 & 85 \\
\hline Men (\%) & $29(55)^{*}$ & $25(29)$ \\
\hline Caucasians & $40(75)^{*}$ & $76(89)$ \\
\hline Age (years) & $44 \pm 12^{*}$ & $61 \pm 8$ \\
\hline Weight (kg) & $75 \pm 3$ & $76 \pm 2$ \\
\hline Height (cm) & $167 \pm 2$ & $164 \pm 1$ \\
\hline $\mathrm{BMI}\left(\mathrm{kg} / \mathrm{m}^{2}\right)$ & $27(22-32)$ & $27(25-31)$ \\
\hline Fragility fractures (\%) & $5(9)$ & $6(11)$ \\
\hline Corticosteroid use (\%) & $3(6)$ & $5(6)$ \\
\hline Bisphosphonate use (\%) & $4(9)$ & $13(15)$ \\
\hline DMARDs (\%) & $7(13)$ & $0(0)$ \\
\hline Total daily calcium intake (mg) & $745(456-1020)^{*}$ & $1045(471-1539)$ \\
\hline Use of supplemental vitamin D (\%) & $19(36)$ & $32(38)$ \\
\hline Hormone therapy $(\%)^{b}$ & $0(0)^{*}$ & $16(19)$ \\
\hline \multicolumn{3}{|l|}{ Areal $\mathrm{BMD}^{\mathrm{C}}\left(\mathrm{g} / \mathrm{cm}^{2}\right)$} \\
\hline $\mathrm{L} 1-\mathrm{L} 4$ & $0.994 \pm 0.179$ & $0.988 \pm 0.156$ \\
\hline Total hip & $0.904 \pm 0.149$ & $0.930 \pm 0.123$ \\
\hline Femoral neck & $0.767 \pm 0.142$ & $0.756 \pm 0.116$ \\
\hline Distal $1 / 3$ radius & $0.740 \pm 0.127$ & $0.644 \pm 0.170$ \\
\hline Ultra distal radius & $0.477 \pm 0.078$ & $0.418 \pm 0.120$ \\
\hline Low BMD/osteopenia (\%) & $18(34)$ & $37(44)$ \\
\hline Osteoporosis (\%) & $6(11)$ & $7(8)$ \\
\hline
\end{tabular}

Data expressed as mean \pm standard deviation, median (interquartile range) or number $(\% N)$ unless specified otherwise

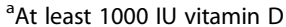

${ }^{\mathrm{b}}$ Postmenopausal women receiving hormone replacement treatment

Intergroup comparison of BMD was not performed between AS and non-AS subjects because of the differences in age and sex

${ }^{*} p<0.05$

$A S$ ankylosing spondylitis, $B M D$ bone mineral density, $B M I$ body mass index $D M A R D$ disease-modifying antirheumatic drug

\section{Comparison of HRpQCT parameters in AS patients with} mSASSS $>0$ vs. $m S A S S S=0$

Intergroup comparisons performed using two-sample $t$ tests showed that AS patients who had mSASSS $>0$ had worse bone microarchitecture than those who had normal mSASSS $(\mathrm{mSASSS}=0)$ (Table 4$)$. Specifically, the high-mSASSS group $(n=28)$ had lower cortical vBMD, greater cortical porosity, and lower cortical thickness at both sites. Bone stiffness and stress also tended to be lower although these results did not reach statistical significance. Trabecular parameters did not differ between the groups. On multivariable regression analysis, the negative effect of high mSASSS tended to be statistically significant for cortical vBMD (radius) and cortical porosity (tibia), after adjusting for age and disease duration $(\beta=-27.1,95 \%$ confidence interval (CI): -56.0 to 1 . $4, p=0.05$; and $\beta=.21,95 \% \mathrm{CI}:-0.01$ to $0.3, p=0.09$ respectively). 
Table 2 Comparison of clinical parameters, HRpQCT, and BMD among AS patients based on sex, mSASSS, and HLA-B27

\begin{tabular}{|c|c|c|c|c|c|c|c|}
\hline \multirow[t]{3}{*}{ Variable } & \multirow{3}{*}{$\begin{array}{l}\text { Total } \\
(N=53)\end{array}$} & \multicolumn{2}{|l|}{ Sex } & \multicolumn{2}{|l|}{ mSASSS } & \multicolumn{2}{|l|}{ HLA-B27 } \\
\hline & & Men & Women & $m S A S S S>0$ & $\mathrm{mSASSS}=0$ & HLA-B27(+) & HLA-B27(-) \\
\hline & & $(n=29)$ & $(n=24)$ & $(n=28)$ & $(n=25)$ & $(n=36)$ & $(n=16)$ \\
\hline Men (\%) & $29(55)$ & - & - & $20(71)$ & $9(36)^{*}$ & $22(61)$ & $6(38)$ \\
\hline Caucasians & $40(75)$ & $20(69)$ & $20(83)$ & $20(71)$ & $20(80)$ & $30(83)$ & $10(63)$ \\
\hline Age (years) & $44 \pm 12$ & $45 \pm 12$ & $43 \pm 11$ & $48 \pm 11^{*}$ & $39 \pm 11$ & $45 \pm 12$ & $40 \pm 11$ \\
\hline Disease duration (years) & $17(7-27)$ & $21(9-28)^{*}$ & $12(4-20)$ & $24(9-32)^{*}$ & $12(4-20)$ & $20(8-28)$ & $11(6-22)$ \\
\hline $\mathrm{BMI}\left(\mathrm{kg} / \mathrm{m}^{2}\right)$ & $27(22-32)$ & $27(25-32)$ & $24(21-32)$ & $27(24-30)$ & $26(22-32)$ & $26(22-29)$ & $23(27-36)$ \\
\hline Current smoking (\%) & $20(38)$ & $13(44)$ & $7(29)$ & $12(43)$ & $8(32)$ & $14(39)$ & $5(31)$ \\
\hline Heavy alcohol use (\%) ${ }^{a}$ & $2(4)$ & $2(7)$ & $0(0)$ & $1(4)$ & $1(4)$ & $1(3)$ & $1(6)$ \\
\hline Corticosteroid use (\%) & $3(6)$ & $1(3)$ & $2(8)$ & $0(0)$ & $2(8)$ & $0(0)$ & $2(13)$ \\
\hline Bisphosphonate use (\%) & $4(9)$ & $3(16)$ & $1(5.3)$ & $2(7)$ & $2(8)$ & $2(5)$ & $2(11)$ \\
\hline Use of DMARDs (\%) & $7(13)$ & $5(17)$ & $2(8)$ & $5(18)$ & $2(8)$ & $3(8)$ & $3(19)$ \\
\hline NSAID use (\%) & $47(89)$ & $26(90)$ & $21(88)$ & $25(89)$ & $22(88)$ & $29(81)$ & $10(63)$ \\
\hline IBD (\%) & $8(18)$ & $3(10)$ & $5(13)$ & $3(10)$ & $5(20)$ & $4(11)$ & $3(19)$ \\
\hline Psoriasis (\%) & $8(18)$ & $5(17)$ & $3(13)$ & $6(20)$ & $2(8)$ & $6(17)$ & $2(13)$ \\
\hline BASDAI & $6.7(4.8-7.9)$ & $5.8(4.3-7.0)^{*}$ & $7.5(5.7-8.4)$ & $6.5(4.3-7.5)$ & $6.8(5.5-8.0)$ & $6.6(4.3-7.5)$ & $7.5(4.7-8.8)$ \\
\hline mSASSS & $2(0-11)$ & $8(1-16)^{*}$ & $0(0-2)$ & - & - & $2(0-15)$ & $1(0-7)$ \\
\hline mSASSS > 0 (\%) & $28(53)$ & $20(69)^{*}$ & $8(33)$ & - & - & $21(58)$ & $6(38)$ \\
\hline Fragility fractures (\%) & $5(9)$ & $4(14)$ & $1(4)$ & $4(14)$ & $1(4)$ & $4(11)$ & $2(13)$ \\
\hline Serum ESR (mm/hour) & $21.9 \pm 22.5$ & $18 \pm 19$ & $25 \pm 25$ & $30.7 \pm 26.9^{*}$ & $12.8 \pm 10.9$ & $21 \pm 23$ & $22 \pm 20$ \\
\hline Serum CRP (mg/l) & $13.3 \pm 16.7$ & $13 \pm 17$ & $11 \pm 15$ & $19.6 \pm 20.1^{*}$ & $6.1 \pm 6.8$ & $13 \pm 18$ & $12 \pm 13$ \\
\hline SAP (IU) & $94 \pm 41$ & $88 \pm 19$ & $103 \pm 60$ & $106.8 \pm 46.6^{*}$ & $80.7 \pm 30.1$ & $92 \pm 41$ & $99 \pm 42$ \\
\hline
\end{tabular}

Data expressed as mean \pm standard deviation, median (interquartile range) or number $(\% N$ ) unless specified otherwise

${ }^{a}$ Heavy alcohol use: $>14$ drinks per week

${ }^{*} p<0.05$, men vs. women

${ }^{* *} p<0.05$, high mSASSS vs. normal mSASSS

${ }^{+} p<0.05, \mathrm{HLA}-\mathrm{B} 27(+)$ vs. HLA-B27(-)

AS ankylosing spondylitis, BASDAl Bath Ankylosing Spondylitis Disease Activity Index, BMD bone mineral density, BMI body mass index, CRP C-reactive protein, $D M A R D$ disease-modifying antirheumatic drug, ESR erythrocyte sedimentation rate, $H R P Q C T$ high-resolution peripheral quantitative computerized tomography, IBD Inflammatory bowel disease, mSASSS modified Stoke Ankylosing Spondylitis Spine Score, NSAID nonsteroidal antiinflammatory drug, SAP Serum

alkaline phosphatase

\section{Sex differences in HRpQCT parameters in AS patients}

Intergroup comparisons performed using two-sample $t$ tests showed that women had worse trabecular microarchitecture than men but cortical bone abnormalities were more predominant in men (Table 4). Trabecular vBMD and bone volume/total volume (BV/TV) were lower in women. Women had fewer, thinner, and more widely spaced trabeculae than men. However, men had lower cortical vBMD at the radius, cortical thickness at the tibia, and greater cortical porosity at both sites. The differences in HRpQCT parameters persisted even after excluding postmenopausal women. No differences existed in bone strength between men and women.

\section{Comparison of HRpQCT characters in AS patients with or without HLA-B27}

AS patients without HLA-B27 antigen $(n=16)$ were found to have lower trabecular vBMD in comparison with AS patients with HLA-B27 (Table 4). In addition, BV/TV and trabecular separation and FEA parameters at the tibia were abnormal in HLA-B27(-) patients. Intergroup comparisons were performed using two-sample $t$ tests.

Regression analysis in patients with AS alone did not suggest that parameters such as the BASDAI and smoking had an influence on bone microarchitecture and strength.

\section{Areal BMD abnormalities in AS patients}

The prevalence of osteoporosis was $10 \%$ (3/29) and $13 \%(3 / 24)$ in men and women with AS respectively. Approximately $31 \%$ of men and $38 \%$ of women had osteopenia or low bone mass and $6 / 8$ postmenopausal women had either osteoporosis or osteopenia. Although men with AS had more cortical bone abnormalities, BMD at the total hip and radius was higher in men than in women (Table 4). Despite women having more trabecular abnormalities at the distal sites on HRpQCT, lumbar spine BMD was similar between men and women. Areal BMD at most sites did not differ based on 
Table 3 Multivariable linear regression analysis assessing AS as an independent predictor of BMD, and bone microarchitecture

\begin{tabular}{|c|c|c|c|c|c|c|c|c|}
\hline \multirow[t]{2}{*}{ HRpQCT } & \multicolumn{4}{|l|}{ Radius } & \multicolumn{4}{|l|}{ Tibia } \\
\hline & $\overline{\beta^{a}}$ & $95 \% \mathrm{Cl}$ & $p$ value & Adj. $R^{2}$ & $\overline{\beta^{a}}$ & $95 \% \mathrm{Cl}$ & $p$ value & $\operatorname{Adj} \cdot R^{2}$ \\
\hline Trabecular vBMD & -15.1 & -33.3 to -3.2 & 0.105 & 0.184 & -17.2 & -35.3 to -1.5 & 0.071 & 0.094 \\
\hline Cortical vBMD & -34.3 & -62.8 to -7.9 & 0.011 & 0.160 & -28.15 & -55.1 to -5.4 & 0.018 & 0.096 \\
\hline Total vBMD & -41.6 & -71.0 to -12.1 & 0.006 & 0.087 & -28.13 & -51.7 to 4.5 & 0.020 & 0.256 \\
\hline Trabecular number & -0.088 & -0.244 to -0.068 & 0.268 & 0.070 & -0.065 & -0.343 to 0.113 & 0.471 & 0.063 \\
\hline Trabecular thickness & -0.004 & -0.008 to 0.001 & 0.087 & 0.217 & -0.004 & -0.010 to 0.003 & 0.260 & 0.001 \\
\hline Trabecular separation & 0.052 & $0.011-0.115$ & 0.105 & 0.072 & 0.060 & -0.017 to 0.137 & 0.128 & 0.063 \\
\hline BV/TV (\%) & -0.013 & -0.028 to -0.003 & 0.106 & 0.184 & -0.014 & -0.030 to -0.001 & 0.070 & 0.094 \\
\hline Cortical thickness & -0.101 & -0.163 to -0.039 & 0.002 & 0.202 & -0.060 & -0.116 to 0.004 & 0.035 & 0.381 \\
\hline Cortical porosity & 0.006 & $0.001-0.010$ & 0.016 & 0.326 & 0.013 & $0.002-0.023$ & 0.016 & 0.323 \\
\hline Stiffness & -0.226 & -0.384 to -0.069 & 0.005 & 0.055 & -0.160 & -0.333 to 0.013 & 0.069 & 0.081 \\
\hline Stress & -5.7 & -9.61 to -1.7 & 0.005 & 0.055 & -4.0 & -8.3 to 0.24 & 0.064 & 0.082 \\
\hline
\end{tabular}

${ }^{\mathrm{a}}$ Beta coefficient represents the difference between patients with AS $(n=53)$ and subjects without AS $(n=85)$, and subjects without AS are the reference category. The model was adjusted for differences in age and sex

Adj. adjusted, $A S$ ankylosing spondylitis, $B M D$ bone mineral density, BV/TV bone volume/trabecular volume, $C l$ confidence interval, $H R p Q C T$ high-resolution peripheral quantitative computerized tomography, $V B M D$ volumetric bone mineral density

HLA-B27 status or mSASSS (Table 4). On multivariable regression analysis, when compared with non-AS subjects $(n=85)$, patients with AS $(n=53)$ had lower BMD at both the total hip and femoral neck even after adjusting for age and sex (Table 5).

\section{Correlation between erythrocyte sedimentation rate, C-reactive protein, and HRpQCT parameters}

We observed significant negative correlations between erythrocyte sedimentation rate (ESR) and tibial vBMD. The correlation coefficients between ESR and vBMD at the distal tibia were $-0.351(p<0.05),-0.382(p<0.001)$, and $0.356(p<0.05)$ for trabecular, cortical, and total vBMD respectively. Cortical thickness $(r=-0.297, p<0.05)$ and BV/ TV $(r=-0.351, p<0.001)$ at the distal tibia also correlated negatively with ESR. Statistically significant inverse correlation was also noted between bone stiffness $(r=-0.293$, $p<0.05)$ and stress $(r=-0.378, p<0.001)$ and serum ESR. Conversely, serum C-reactive protein (CRP) was not correlated with HRpQCT parameters. No correlation existed between areal BMD and ESR or CRP.

\section{Discussion}

Our results suggest that AS patients have lower cortical vBMD, lower cortical thickness, higher cortical porosity, and lower bone stiffness and stress when compared with non-AS controls. These abnormalities might partly explain the cause for fractures in AS. Areal BMD at the lumbar spine and distal radius did not differ between AS and nonAS subjects despite differences in bone microarchitecture.

HRpQCT-based measures of bone quality can predict fractures independent of BMD [29-31]. We found that bone stiffness and stress (as estimated by FEA) were significantly lower at the distal radius in AS patients. These abnormalities were not as pronounced at the distal tibia, probably because of the protective effect of skeletal loading.

Our results confirm the findings of a recent crosssectional study in which cortical vBMD at the distal radius and trabecular vBMD at the distal tibia were reduced in AS patients [32]. Similar to our study, the authors noted that cortical porosity was higher in AS patients. It is now thought that VFs are associated with lower vBMD and cortical thinning [32]. However, certain methodological differences exist between our study and the study by Klingberg et al. The main differences are that only men were studied by Klingberg et al., and cases and controls were not ethnically or geographically matched introducing bias from unmeasured confounders. In addition, the description of the abnormalities of bone microstructure in patients who had VFs were based on a small sample $(n=8)$ and only morphometric VFs belonging to Genant grade 1 category (12/14 VFs) were studied [32]. Genant grade 1 fractures are not always caused by osteoporosis and may not predict future VFs. Although diseasemodifying antirheumatic drugs (DMARDs; methotrexate and sulfasalazine) have a neutral effect on areal BMD, use of TNFi is associated with improvement in spine and hip BMD in AS patients [33-35]. However, Klingberg et al. did not account for the influence of methotrexate, sulfasalazine, or TNFi despite the fact that a significant number of patients had received such medications. Conversely, in our study, the use of bisphosphonates, DMARDs, and steroids was negligible and no patient had received TNFi.

HLA-B27 might have a role in mediating bone loss in AS. HLA-B27 transgenic rats experience bone loss due to increased osteoclastogenesis and bone resorption [17]. However, data on the effect of HLA-B27 on bone 
Table 4 Comparison of HRpQCT and BMD among patients with AS based on sex, mSASSS, and HLA-B27

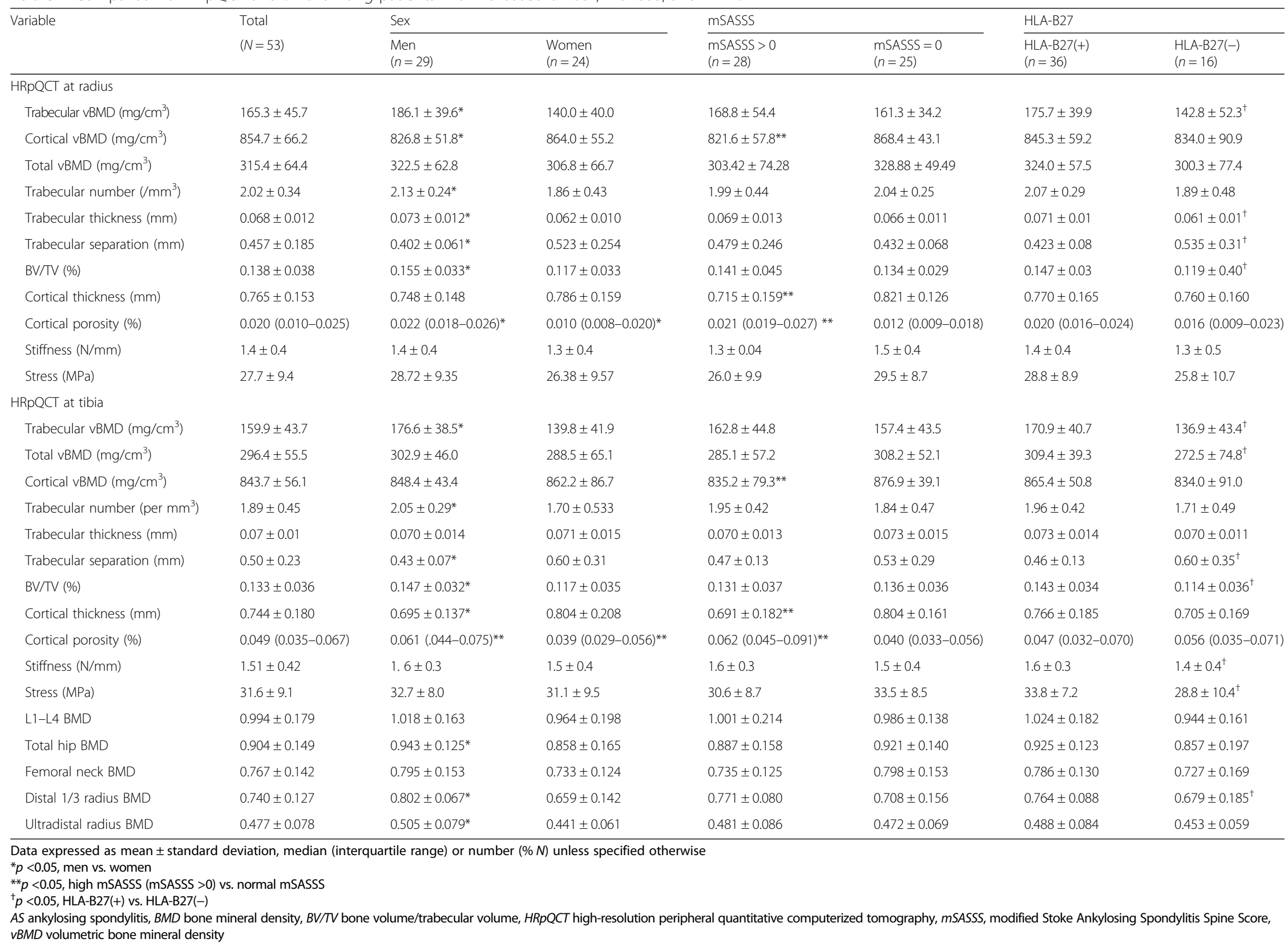


Table 5 Multivariable linear regression analysis assessing AS as an independent predictor of areal BMD

\begin{tabular}{lllcc}
\hline & $\beta^{a}$ & $95 \%$ confidence interval & $p$ value & Adjusted $R^{2}$ \\
\hline L1-L4 spine & -0.02 & -0.10 to 0.06 & 0.656 & 0.097 \\
Total hip & -0.11 & -0.17 to -0.05 & 0.000 & 0.223 \\
Femoral neck & -0.09 & -0.15 to -0.37 & 0.001 & 0.242 \\
Distal 1/3 radius & 0.01 & -0.03 to 0.04 & 0.926 & 0.316 \\
Ultradistal radius & -0.02 & -0.05 to 0.02 & 0.421 & 0.316 \\
\hline
\end{tabular}

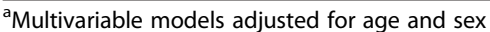

$A S$ ankylosing spondylitis, $B M D$ bone mineral density

loss in AS patients are inconsistent. In our study, the HLA-B27(-) AS patients had worse trabecular parameters, bone stiffness, and stress than the HLA-B27(+) patients. This supports the results of a previous study [36] that reported a higher prevalence of clinical VFs in HLA-B27(-) patients (9.9 vs. $4.8 \%$ ) than HLA-B27(+) patients. In contrast, another study found that AS patients with low BMD or VFs were more likely to be HLA-B27(+), but the difference was not statistically significant [37].

We found important sex differences in bone microarchitecture and strength in AS. Although men had higher areal BMD at the total hip and distal radius than women, the cortical bone vBMD and microarchitecture were worse in men. Conversely, trabecular parameters were worse in women. Men with AS had greater cortical porosity despite the fact that cortical porosity is worse in healthy women than men during young adulthood [38]. This is possibly due to men having more severe disease than women. Factors such as menopause and systemic inflammation are probably responsible for the abnormal trabecular microarchitecture in AS women [38, 39], which is worse than in men. We observed no sex differences in bone stiffness in AS patients. However, it is established that in young healthy adults, bone stiffness is lower in women than in men [40]. Longstanding disease and higher mSASSS in men may have caused a stronger insult on FEA parameters in men masking the sex differences. Our results thus suggest that sex differences in bone microarchitecture and strength are attenuated by AS.

We found that patients with mSASSS $>0$ tended to have poor cortical bone microarchitecture. These results were partly influenced by differences in age and disease duration, however, and need to be studied further. Abnormal cortical microarchitecture in those with mSASSS $>0$ may indicate that systemic bone loss occurs in parallel with radiological progression of AS. In the study by Klingberg et al. [32], the mSASSS correlated with abnormal cortical porosity and cortical vBMD.

Our results showing that AS patients have abnormal cortical microarchitecture are important given that the microstructure of cortical bone is a key determinant of bone fragility [31, 41-43]. Cortical microarchitecture was negatively affected at both the distal radius and tibia, suggesting that mechanical loading may not ameliorate the catabolic actions of inflammation on cortical bone. Age-related loss of cortical bone does not begin until middle age or late life in women [44, 45]. Patients with AS had poor cortical bone structure despite being young and it is likely that AS exaggerates loss of cortical bone. Abnormal cortical bone parameters in AS are probably due to systemic inflammation, vitamin D deficiency, secondary hyperparathyroidism, abnormal skeletal loading due to abnormal gait and posture, low peak bone mass, low BMI, low lean mass, hypogonadism, malabsorption, inflammatory bowel disease (IBD), and trabecularization of cortical bone [46-50].

Systemic inflammation plays a key role in causing bone loss, as suggested by the negative correlation between ESR and HRpQCT parameters. AS is characterized by ossification of the enthuses and formation of osteophytes but paradoxically there is loss of trabecular bone adjacent to the sites of inflammation. Trabecular and cortical compartments appear to have different reactions to inflammation. Although a high BASDAI indicates severe AS, we found that it was not associated with poor bone microarchitecture. This is in concordance with past reports that the BASDAI may not differentiate AS patients with low BMD [34, 35]. Subjective measures such as the BASDAI may not reflect longstanding inflammation. Furthermore, all our patients had a high BASDAI and the lack of variability in our population may have influenced our results.

Our study has both limitations and strengths. The main limitations include the cross-sectional design, small sample size, and lack of generalizability in non-Caucasian patients. Despite the small size of our study, it is the largest study of bone microarchitecture in AS patients (including both men and women), to our knowledge. We may have missed some differences in bone microarchitecture in the secondary analyses due to lack of power. All patients had active disease and hence the results may only reflect abnormalities related to severe inflammation. Next, $18 \%$ of patients had IBD and this may have affected our results. Also, we did not study testosterone levels and bone turnover. Another limitation is that we did not have data on smoking, alcoholism, and physical activity in the non-AS group. Finally, we could not study the discriminative ability of HRpQCT to identify patients with high fracture risk since the number of patients with fractures was small. Our study has several strengths including the assessment of bone strength and stiffness in AS patients for the first time. This is only the second study to provide detailed information of bone microarchitecture in patients with AS. Our results may guide future research on the prediction and management of fragility fractures in AS patients. We were able to generate important findings that both 
trabecular and cortical compartments are affected in AS. This information can be used to design future studies aimed at assessing changes in bone strength in response to NSAIDs or TNFi. Finally, the potential confounding effect of TNFi was eliminated by excluding subjects who had been on treatment with TNFi, whereas previous studies were unable to do so [32, 33].

\section{Conclusions}

We conclude that vBMD, bone microstructure, and strength are abnormal in AS patients with severe disease. Sex, mSASSS, and HLA-B27 are determinants of bone microarchitecture in AS. Future research should investigate whether abnormal bone microarchitecture and strength are predictive of fractures in AS. The effect of TNFi on bone strength also needs to be studied.

\begin{abstract}
Abbreviations
AS: Ankylosing spondylitis; BASDAl: Bath Ankylosing Spondylitis Disease Activity Index; BMD: Bone mineral density; BMI: Body mass index; BV/TV: Bone volume/ total volume; CaMOS: Canadian Multicenter Osteoporosis Study; Cl: Confidence interval; CRP: C-reactive protein; DMARD: Disease-modifying antirheumatic drug; DXA: Dual-energy X-ray absorptiometry; ESR: Erythrocyte sedimentation rate; FEA: Finite element analysis; HT: Hormone therapy; IBD: Inflammatory bowel disease; HRpQCT: High-resolution peripheral quantitative computerized tomography; L: Interleukin; mSASSS: Modified Stoke Ankylosing Spondylitis Spine Score; TNFi: Tumor necrosis factor inhibitors; VBMD: volumetric bone mineral density; VF: Vertebral fracture.
\end{abstract}

\section{Competing interests}

This study was funded through an investigator-initiated research grant from AMGEN, Canada. However, AMGEN had no role in the design of the study, the conduct of the analysis, interpretation of the results, or the preparation of the manuscript.

No nonfinancial conflicts of interest exist for any of the authors.

\section{Authors' contributions}

$\mathrm{NNH}$ and $\mathrm{AMC}$ were actively involved in formulating the research question, designing the study, extracting data, conducting the statistical analysis, and preparing the manuscript. ES and LF were actively involved in data collection, FEA, and preparing the manuscript. JMR was actively involved in designing the study, conducting the statistical analysis, and preparing the manuscript. HM-B and RGJ were involved in interpreting the data and preparing the manuscript. $\mathrm{RDI}$ was actively involved in formulating the research question, designing the study, data collection, conducting the statistical analysis, and preparing the manuscript. All authors read and approved the manuscript.

\section{Acknowledgements}

The authors thank the staff at the Spondylitis and Osteoporosis Clinics at the University Health Network, Toronto, ON, Canada for coordinating the study. AMC was supported by a 5-year Canadian Institute of Health Research Senior Investigator Award.

Received: 24 September 2015 Accepted: 24 November 2015 Published online: 24 December 2015

\section{References}

1. Bakland G, Gran JT, Nossent JC. Increased mortality in ankylosing spondylitis is related to disease activity. Ann Rheum Dis. 2011;70:1921-5.

2. Muñoz-Ortego J, Vestergaard P, Rubio JB, Wordsworth P, Judge A, Javaid MK, et al. Ankylosing spondylitis is associated with an increased risk of vertebral and nonvertebral clinical fractures: a population-based cohort study. J Bone Miner Res. 2014;29:1770-6.

3. Prieto-Alhambra D, Muñoz-Ortego J, De Vries F, Vosse D, Arden NK, Bowness $P$, et al. Ankylosing spondylitis confers substantially increased risk of clinical spine fractures: a nationwide case-control study. Osteoporos Int. 2015;26:85-91

4. Dursun N, Sarkaya S, Ozdolap S, Dursun E, Zateri C, Altan L, et al. Risk of falls in patients with ankylosing spondylitis. J Clin Rheumatol. 2015;21:76-80.

5. Fatemi $G$, Gensler LS, Learch TJ, Weisman MH. Spine fractures in ankylosing spondylitis: a case report and review of imaging as well as predisposing factors to falls and fractures. Semin Arthritis Rheum. 2014;44:20-4.

6. Klingberg E, Geijer M, Gothlin J, Mellström D, Lorentzon M, Hilme E, et al. Vertebral fractures in ankylosing spondylitis are associated with lower bone mineral density in both central and peripheral skeleton. J Rheumatol. 2012;39:1987-95.

7. Jun JB, Joo KB, Her MY, Kim TH, Bae SC, Yoo DH, et al. Femoral bone mineral density is associated with vertebral fractures in patients with ankylosing spondylitis: a cross-sectional study. J Rheumatol. 2006;33:1637-41.

8. Donnelly S, Doyle DV, Denton A, Rolfe I, McCloskey EV, Spector TD. Bone mineral density and vertebral compression fracture rates in ankylosing spondylitis. Ann Rheum Dis. 1994;53:117-21.

9. Arends S, Spoorenberg A, Bruyn GA, Houtman PM, Leijsma MK, Kellenberg CGM, et al. The relation between bone mineral density, bone turnover markers, and vitamin D status in ankylosing spondylitis patients with active disease: a cross-sectional analysis. Osteoporos Int. 2011;22:1431-9.

10. Ghozlani I, Ghazi M, Nouijai A, Mounach A, Rezqi A, Achemlal L, et al. Prevalence and risk factors of osteoporosis and vertebral fractures in patients with ankylosing spondylitis. Bone. 2009:44:772-6.

11. NIA workshop on aging and bone quality. Bethesda, MD; September 3-4, 1992. Proceedings. Calcif Tissue Int. 1993:53 Suppl 1:S1-180.

12. Schuit SC, van der Klift M, Weel AE, de Laet CE, Burger H, Seeman E, et al. Fracture incidence and association with bone mineral density in elderly men and women: the Rotterdam Study. Bone. 2004;34:195-202.

13. Gilgil E, Kacar C, Tuncer T, Bütün B. The association of syndesmophytes with vertebral bone mineral density in patients with ankylosing spondylitis. J Rheumatol. 2005;32:292-4.

14. Vander Cruyssen B, Vastesaeger N, Collantes-Estévez E. Hip disease in ankylosing spondylitis. Curr Opin Rheumatol. 2013;25:448-54.

15. Devogelaer JP, Maldague B, Malghem J, Nagant de Deuxchaisnes C. Appendicular and vertebral bone mass in ankylosing spondylitis. A comparison of plain radiographs with single- and dual-photon absorptiometry and with quantitative computed tomography. Arthritis Rheum. 1992;35:1062-7.

16. Rauner M, Stupphann D, Haas M, Fert I, Glatigny S, Sipos W, et al. The HLA-B27 transgenic rat, a model of spondyloarthritis, has decreased bone mineral density and increased RANKL to osteoprotegrin mRNA ratio. J Rheumatol. 2009;36:120-6.

17. Rauner M, Thiele S, Fert I, Araujo LM, Layh-Schmitt G, Colbert RA, et al. Loss of bone strength in HLA-B27 transgenic rats is characterized by a high bone turnover and is mainly osteoclast-driven. Bone. 2015;75:183-91.

18. Cheung AM, Adachi JD, Hanley DA, Kendler DL, Davison KS, Josse R, et al. High-resolution peripheral quantitative computed tomography for the assessment of bone strength and structure: a review by the Canadian Bone Strength Working Group. Curr Osteoporos Rep. 2013;11:136-46.

19. MacNeil JA, Boyd SK. Improved reproducibility of high-resolution peripheral quantitative computed tomography for measurement of bone quality. Med Eng Phys. 2008;30:792-9.

20. Vilayphiou N, Boutroy S, Sornay-Rendu E, Van Rietbergen B, Munoz F, Delmas PD, et al. Finite element analysis performed on radius and tibia $\mathrm{HRpQCT}$ images and fragility fractures at all sites in postmenopausal women. Bone. 2010;46:1030-7.

21. van der Linden S, Valkenburg HA, Cats A. Evaluation of diagnostic criteria for ankylosing spondylitis. A proposal for modification of the New York criteria. Arthritis Rheum. 1984;27:361-8.

22. Zochling J. Measures of symptoms and disease status in ankylosing spondylitis: Ankylosing Spondylitis Disease Activity Score, Ankylosing Spondylitis Quality of Life Scale, Bath Ankylosing Spondylitis Disease Activity Index, Bath Ankylosing Spondylitis Functional Index, Bath Ankylosing Spondylitis Global Score, Bath Ankylosing Spondylitis Metrology Index, Dougados Functional Index, and Health Assessment Questionnaire for the Spondylarthropathies. Arthritis Care Res. 2011;63:547-58.

23. Wanders A, Landewé RB, Spoorenberg A, Dougados M, van der Linden S, Mielants $\mathrm{H}$, et al. What is the most appropriate radiologic scoring method for ankylosing spondylitis? A comparison of the available methods based on the Outcome Measures in Rheumatology Clinical Trials filter. Arthritis Rheum. 2004;50:2622-32.

24. Kreiger N, Tenenhouse A, Joseph L, Mackenzie T, Poliquin S, Brown JP, et al. The Canadian Multicentre Osteoporosis Study (CaMos): background, rationale, methods. Can J Aging. 1999;18:376e387. 
25. Kanis JA, Melton 3rd LJ, Christiansen C, Johnston CC, Khaltaev N. The diagnosis of osteoporosis. J Bone Miner Res. 1994;9:1137-41.

26. Schousboe JT, Shepherd JA, Bilezikian JP, Baim S. Executive summary of the 2013 International Society for Clinical Densitometry Position Development Conference on bone densitometry. J Clin Densitom. 2013;16:455-66.

27. Cheung AM, Majumdar S, Brixen K, Chapurlat R, Fuerst T, Engelke $K$, et al. Effects of odanacatib on the radius and tibia of postmenopausal women: improvements in bone geometry, microarchitecture, and estimated bone strength. J Bone Miner Res. 2014;29:1786-94.

28. Burghardt AJ, Buie HR, Laib A, Majumdar S, Boyd SK. Reproducibility of direct quantitative measures of cortical bone microarchitecture of the distal radius and tibia by HR-pQCT. Bone. 2010;47:519-28.

29. van Rietbergen $B$, Weinans $H$, Huiskes $R$, Odgaard A. A new method to determine trabecular bone elastic properties and loading using micromechanical finite-element models. J Biomech. 1995;28:69-81.

30. Rudäng R, Darelid A, Nilsson M, Mellström D, Ohlsson C, Lorentzon M. X-rayverified fractures are associated with finite element analysis-derived bone strength and trabecular microstructure in young adult men. J Bone Miner Res. 2013;28:2305-16.

31. Chevalley T, Bonjour JP, van Rietbergen B, Rizzoli R. Fracture history of healthy premenopausal women is associated with a reduction of cortical microstructural components at the distal radius. Bone. 2013;55:377-83.

32. Klingberg E, Lorentzon M, Göthlin J, Mellström D, Geijer M, Ohlsson C, et al. Bone microarchitecture in ankylosing spondylitis and the association with bone mineral density, fractures, and syndesmophytes. Arthritis Res Ther. 2013;15:R179.

33. Haroon NN Sriganthan J, Al Ghanim N, Inman RD, Cheung AM. Effect of TNF-alpha inhibitor treatment on bone mineral density in patients with ankylosing spondylitis: a systematic review and meta-analysis. Semin Arthritis Rheum. 2014:44(2):155-61

34. van der Weijden MA, van Denderen JC, Lems WF, Heymans MW, Dijkmans BA, van der Horst-Bruinsma IE. Low bone mineral density is related to male gender and decreased functional capacity in early spondylarthropathies. Clin Rheumatol. 2011;30:497-503.

35. Taylan A, Sari I, Akinci B, Bilge S, Kozaci D, Akar S, et al. Biomarkers and cytokines of bone turnover: extensive evaluation in a cohort of patients with ankylosing spondylitis. BMC Musculoskelet Disord. 2012;13:191.

36. Feldtkeller $E$, Vosse D, Geusens $P$, van der Linden S. Prevalence and annual incidence of vertebral fractures in patients with ankylosing spondylitis. Rheumatol Int. 2006;26:234-9.

37. Ulu MA, Batmaz I, Dilek B, Çevik R. Prevalence of osteoporosis and vertebral fractures and related factors in patients with ankylosing spondylitis. Chin Med J (Engl). 2014;127:2740-7.

38. Macdonald HM, Nishiyama KK, Kang J, Hanley DA, Boyd SK. Age-related patterns of trabecular and cortical bone loss differ between sexes and skeletal sites: a population-based HR-pQCT study. J Bone Miner Res. 2011;26:50-62.

39. Nicks KM, Amin S, Atkinson EJ, Riggs BL, Melton LJ 3rd, Khosla S. Relationship of age to bone microstructure independent of areal bone mineral density. J Bone Miner Res. 2012;27:637-44.

40. Dalzell N, Kaptoge S, Morris N, Berthier A, Koller B, Braak L, et al. Bone micro-architecture and determinants of strength in the radius and tibia: age-related changes in a population-based study of normal adults measured with high-resolution pQCT. Osteoporos Int. 2009;20:1683-94.

41. Burghardt AJ, Kazakia GJ, Ramachandran S, Link TM, Majumdar S. Age- and gender-related differences in the geometric properties and biomechanical significance of intracortical porosity in the distal radius and tibia. J Bone Miner Res. 2010;25:983-93.

42. Rudäng R, Darelid A, Nilsson M, Mellström D, Ohlsson C, Lorentzon M. X-rayverified fractures are associated with finite element analysis-derived bone strength and trabecular microstructure in young adult men. J Bone Miner Res. 2013;28(11):2305-16.

43. Ostertag A, Collet C, Chappard C, Fernandez S, Vicaut E, Cohen-Solal M, et al. A case-control study of fractures in men with idiopathic osteoporosis: fractures are associated with older age and low cortical bone density. Bone. 2013;52:48-55

44. Riggs BL, Melton lii 3rd LJ, Robb RA, Camp JJ, Atkinson EJ, Peterson JM, et al. Population-based study of age and sex differences in bone volumetric density, size, geometry, and structure at different skeletal sites. J Bone Miner Res. 2004;19:1945-54.

45. Riggs BL, Melton LJ, Robb RA, Camp JJ, Atkinson EJ, McDaniel L, et al. A population-based assessment of rates of bone loss at multiple skeletal sites: evidence for substantial trabecular bone loss in young adult women and men. J Bone Miner Res. 2008;23:205-14.

46. Passalent LA, Soever LJ, O'Shea FD, Inman RD. Exercise in ankylosing spondylitis: discrepancies between recommendations and reality. J Rheumatol. 2010;37:835-41.

47. El Maghraoui A, Borderie D, Cherruau B, Edouard R, Dougados M, Roux C. Osteoporosis, body composition, and bone turnover in ankylosing spondylitis. J Rheumatol. 1999;26:2205-9.

48. Klingberg E, Lorentzon M, Mellstrom D, Geijer M, Göthlin J, Hilme E, et al. Osteoporosis in ankylosing spondylitis-prevalence, risk factors and methods of assessment. Arthritis Res Ther. 2012;14:R108.

49. Bot SDM, Caspers M, Van Royen BJ, Toussaint HM, Kingma I. Biomechanical analysis of posture in patients with spinal kyphosis due to ankylosing spondylitis: a pilot study. Rheumatology. 1999;38:441-3.

50. Del Din S, Carraro E, Sawacha Z, Guiotto A, Bonaldo L, Masiero S, et al. Impaired gait in ankylosing spondylitis. Med Biol Eng Comput. 2011;49:8

\section{Submit your next manuscript to BioMed Central and we will help you at every step:}

- We accept pre-submission inquiries

- Our selector tool helps you to find the most relevant journal

- We provide round the clock customer support

- Convenient online submission

- Thorough peer review

- Inclusion in PubMed and all major indexing services

- Maximum visibility for your research

Submit your manuscript at www.biomedcentral.com/submit

C Biomed Central 